\title{
Commentary: Setting the standard: The necessity of internationalizing residency training programs
}

\author{
Danielle E. Babb, DO, ${ }^{a}$ and Tomás A. Salerno, MD $^{\mathrm{b}}$
}

\footnotetext{
From the ${ }^{\mathrm{a}}$ Department of Anesthesiology, Perioperative Medicine, and Pain Management, and the ${ }^{\mathrm{b}}$ Division of Cardiothoracic Surgery, Jackson Memorial Hospital and the University of Miami Miller School of Medicine, Miami, Fla.

Disclosures: Authors have nothing to disclose with regard to commercial support.

Received for publication Oct 25, 2018; accepted for publication Oct 26, 2018; available ahead of print Nov 30, 2018.

Address for reprints: Tomás A. Salerno, MD, Division of Cardiothoracic Surgery, Jackson Memorial Hospital and the University of Miami Miller School of Medicine, 1611 NW 12th Ave, ET 3072, Miami, FL 33136 (E-mail: TSalerno@med.miami.edu).

J Thorac Cardiovasc Surg 2019;157:2547-8

$0022-5223 / \$ 36.00$

Copyright (C) 2018 by The American Association for Thoracic Surgery

https://doi.org/10.1016/j.jtcvs.2018.10.118
}

Vinch and colleagues ${ }^{1}$ provide insight on how much the field of thoracic surgery in Colombia has evolved as a result of and been improved by internationalizing surgeons' opportunities for additional training. This unique historical perspective on a surgery program provides readers with an opportunity to compare and contrast international training differences. Although there appears to be a new combined cardiothoracic training program beginning in Colombia, Vinch and colleagues ${ }^{1}$ bring attention to a much broader issue. It is unfortunate that it may take years, if not decades, for advanced surgical skills/technology to become the standard of care in our developing neighboring countries.

Global health is increasingly burdened by the high costs of treating diseases and deficits of trained specialized surgeons. ${ }^{2}$ Since 2011, the Accreditation Council for Graduate Medical Education Surgery Residency Review Committee and the American Board of Surgery approved international electives for credit toward residency graduation requirements, as long as the rotations meet Accreditation Council for Graduate Medical Education Surgery Residency Review Committee core competencies. ${ }^{3}$ Since then, many institutions in the United States have made international opportunities available to not only provide outreach, but also to diversify training experiences of our physicians. In 2015, there were 34 surgical residency training programs offering global surgical rotations, up from 23 just 5 years previously. ${ }^{4}$ Africa was noted to be the most common destination with 23 programs. Eleven other programs were located in either Central or South America, or the Caribbean. ${ }^{4}$ The benefits of these programs are 2-fold. Participating residents and fellows across specialties express better understanding of cultural competence, unique social issues, and economic and political influences as they relate to daily high demand.

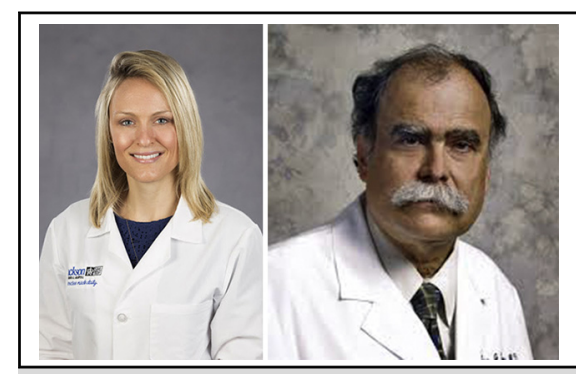

Danielle E. Babb, DO, and Tomás A. Salerno, MD

Central Message

Residency training in surgical specialties should have a hemispheric experience that broadens the experience of trainees.

See Article page 2542.

practice. ${ }^{5}$ Resident physicians also learn how to practice in places where resources may be scarce, returning home with greater appreciation for fiscal responsibility. ${ }^{6}$ Larger academic institutions, such as Massachusetts General Hospital, have piloted global surgical training programs as an initiative to train surgeons beyond native residents through international partnerships. The objective of these program is to "enhance surgical expertise and contribute to the number and quality of specialized surgeons around the world." 2

Current review of the surgery training programs in the United States reveals that many of these programs not only allow, but also encourage international rotation experiences, either by accepting international medical students and resident physicians to their institutions, or by allowing home resident physicians to rotate internationally in the core general surgery or base training. Many institutions also participate in volunteer surgical missions and humanitarian disaster relief initiatives. There are few training institutions in the United States that allow cardiothoracic fellows to formally rotate internationally. This may be due to the high demand of core competencies, lack of international partnerships, limitations of time, cost, or a combination of all of these. What we do know for sure is this is an area of internationalization that is lacking despite incredibly

On the other hand, when international surgeons come to the United States for rotations, they can rarely scrub in with surgical cases or even touch patients. This is usually due to 
hospital policies regarding licensure, insurance, or liability. This is an unfortunate discrepancy. A novel concept would be for medical device companies to support programs aimed at protecting time of teaching faculty, and providing resources for creation of simulation programs in conjunction with academic institutions in the United States. This would allow international surgeons to further their learning skills and techniques and participate in more than an observership program.

Vinch and colleagues ${ }^{1}$ suggest that there is the need for global initiatives aimed at providing international rotations and partnerships. As world leaders in teaching institutions, we must expand this area of medicine to include advanced surgical fellowship positions and beyond. As more international programs are created, outcomes and survey data could be collected to give this concept the increased exposure it needs, allowing these programs to become the new standard for training for our physicians.

\section{References}

1. Vinch EE. General thoracic surgery as a subspecialty in Colombia. J Thorac Cardiovasc Surg. 2019;157:2542-6.

2. Chao TE, Riesel JN, Anderson GA, Mullen JT, Doyle J, Briggs SM, et al. Building a global surgery initiative through evaluation, collaboration, and training: the Massachusetts general hospital experience. J Surg Educ. 2015;72:E21-8.

3. Kang D, Siddigui S, Weiss H, Sifri Z, Krishnaswami S, Price R, et al. Are we meeting ACGME core competencies? A systematic review of literature on international surgical rotations. Am J Surg. 2018;216:782-6.

4. Knudson MM, Tarpley MJ, Numann PJ. Global surgery opportunities for U.S. surgical residents: an interim report. J Surg Educ. 2015;72:E60-5.

5. Tarpley M, Hansen E, Tarpley JL. Early experience in establishing and evaluating an ACGME-approved international general surgery rotation. J Surg Educ. 2013; 70:709-14.

6. Bhullar JS, Bindroo S, Kassem KM, Mittal V. ACGME-recognized international surgery rotation: a step in the right direction? Or testing unknown waters. Am Surg. 2015;81:E190-1. 